REVISTA CHILENA DE LITERATURA

Noviembre 2021, Número 104, 151-217

\title{
ANTOLOGÍA: \\ NEWEN TXALCAN ZUGU / PALABRA DE FUERZA DE TRUENO
}

Selección y edición de María Soledad Falabella Luco 



\section{FAUMELISA MANQUEPILLAN CALFULEO}

\section{Paseo Ahumada}

Era una mujer que cada semana, iba del trabajo al Paseo Ahumada.

Buscaba un sombrero entre las miradas, para cobijarse porque se asustaba.

En el Barrio Alto

se le encontraba, con un delantal

vestida de nana, con un niño rubio, que a veces besaba.

En el Paseo Ahumada, siempre cabizbaja, su mirada lejos, se le observaba.

Un ruego en la boca siempre entonaba, en el Paseo Ahumada.

Atenta al cartero siempre esperaba, a que alguna carta se le entregara.

¿No vendrá del Sur?

ella preguntaba, en el Paseo Ahumada.

Era una mujer, que delantal llevaba, soñando su tierra, siempre esperanzada, queriendo volver con su familia amada, en el Paseo Ahumada. 


\section{Esta capital,}

(a veces contaba, en las largas cartas

que siempre enviaba)

entre ruido y humo, me tiene atrapada.

¡Ayúdenme a salir, del Paseo Ahumada!

De Sueños de Mujer/Zomo Pewma, Temuco, Edición propia/Universidad de la Frontera, 2000, p. 42-43. 


\section{Müley filu kamüley filu}

Apoley filu tañilonco mew

Ta ñi mollfuñ lafken mew ka kakül küleyeygun

Müleygun ta ñi pel ka ta ñi ruku mew

Kiñeke komkeygun ta ñi ge, fey mew lelitukeygun

Lelitun mew güñunküleygun tañi pütra püle

Günülchekey famew kütranküley chumüll günagen

Fillke filu nieygun tañi kewün ka matu amukeygun

Ta ñi müllo puwkeygun ka femechi niegen

Ikeygun ta ñi che gen femechi tremkeygun

Filu püle mew mogelen ta inche

Weza kan küme künowi

Geyku fün ta ñi kalül

Fentren ñam zugu müley tañi trawa mew. 


\section{Culebras \& Serpientes}

Tengo culebras que invaden mis sentidos.

Entre mis mares de sangre se retuercen.

Se aposentan en mi garganta y en mi pecho.

Algunas se asoman a mirar desde mis ojos.

Vigilantes se retuercen en mi vientre, provocando hambres que me duelen cuando muerden.

Diferentes se apoderan de mi lengua urgente viajan

a mi cerebro y me cautivan.

Succionando mi materia van creciendo.

Yo vivo invadida de serpientes,

en males y bienes se convierten.

Se estremece este mi cuerpo palpitante

de tanta carga delirante entre mis pieles.

De Likan kürra ñi purrun, Edición propia, 2017, p. 46. 


\section{Ancestralidad}

Dedicado a mi hija Fernanda que habita en el wenumapu

Habitan en mí, todos mis muertos.

Cientos y cientos me confluyen.

Se fusionan en los pliegues de mis rasgos, corren como ríos torrentosos

en mi sangre.

Habitantes son de esta piel que me cubre, viajan desde el pasado hasta mis ojos arrastrando mis edades.

Comprendo también que mis herencias son de cuerpo, pensamiento espíritu alma y territorios.

Hoy me reúno con mis antiguos ancestros, con mis contemporáneos ancestros, y yo también ancestra.

(Inédito) 
Faumelisa Manquepillan Calfuleo (Lanco, 1960). Poeta, artesana y cantautora mapuche-williche. Publicó su libro bilingüe Sueños de Mujer/ Pewma Zomo (2000), con apoyo de la Corporación de Desarrollo Indígena. Ha publicado también en la revista Pentukun 8 del Instituto de Estudios Indígenas de la UFRO de Temuco y en el libro de ensayo, poesía y documentos Futawillimapu (2000), publicado por CONADI y la Universidad de Los Lagos. Ha expuesto sus trabajos de artesanía y sus cantos en diversas ferias regionales, nacionales e internacionales. Fue antologada en los libros 20 poetas mapuche contemporáneos (2003) y La memoria iluminada (2007). En 2008 participa como artista mapuche en el acto de clausura de la Segunda Bienal de Arte Indígena. En 2009 publica la segunda edición de su libro Sueños de Mujer/Pewma Zomo (CONADI). Hoy es candidata a Senadora de la República por la Región de los Ríos. 


\section{LEONEL LIENLAF LIENLAF}

\section{Boceto para una cartografía en verde opaco y barro}

No es este el relato de mundos ya idos

ya olvidados,

ya ocultos en años.

Es un viaje

por varias tierra_suelos

sendero oscuro_claros

que se abren misteriosos ante tus ojos

como brisa

como viento

como nubes.

Está ahí el secreto

en la piedra que pisas cada día en los caminos

en los musgos

en las plantas

en el viento.

No busques entonces los augurios fáciles

porque no hay destino

solo ráfagas de viento entre las ramas.

De Kogen,

Santiago, Del Aire Ediciones, 2014, p. 9 


\section{Soñe_ando}

Y cómo fue preguntas en miradas

$y$ yo te sueño y cuento

que vagaba a orillas de un gran río detenido

cuando una nube negra

se posó como un pájaro sobre el horizonte

de pronto algo se quebró bajo mis pies

y el mar nació con furia en mis recuerdos.

Luego pareció que el mundo fuese mudo

Hambre Frío Calor

costras que se pegan a la espalda

culebras azules se amarraban a mi cintura

lenguas de fuego bailaban a mi alrededor

de pronto sopló un viento luminoso

estaba sentado sobre un banco de piedra blanca

y el fuego estaba allí, mirándome.

De Kogen,

Santiago, Del Aire Ediciones, 2014, p. 26. 


\section{Murmullos que fueron}

No prestes atención a esos murmullos

que se agitan una y otra vez

son lejanos lamentos de olvidadas tristezas

voces putrefactas bajo el agua estancada

lágrimas ásperas de vertientes mudas

sequedades antiguas:

aguas muertas.

De Kogen,

Santiago, Del Aire Ediciones, 2014, p. 33. 
Leonel Lienlaf Lienlaf (Alepue, 1969). Poeta y músico mapuche chileno que escribe en mapudungun y español. Su primer poemario, Se ha despertado el ave de mi corazón, escrito en mapudungun y español, lo publicó en 1989 y al año siguiente fue distinguido con el Premio Municipal de Literatura de Santiago, convirtiéndose en el primer poeta mapuche en obtener ese galardón. Desde ese entonces, ha publicado el libro Etnosemiótica de la literatura oral mapuche (1991), en coautoría con Carlos Aldunate y Pedro Megge; el disco compacto Canto y poesía mapuche (1997), financiado por la embajada de Finlandia; Palabras soñadas (Pewma Dungu) (2003), poemario bilingüe; Voces mapuches (2002), Kogen, poesía (2014), Epu zuam (2016), poemario bilingüe, y La luz cae vertical, antología bilingüe (2018). La poesía de Lienlaf no busca confrontar a la cultura chilena, sino más bien reconocer la presencia de las creencias de su pueblo en el espacio cotidiano. 


\section{ROXANA MIRANDA RUPAILAF}

\section{Ritual de la ausencia y sus sombras}

Quemaré el laurel en los rincones de la casa en que nos consumimos.

Ahora sé que no volverá el movimiento a los olores.

Recogeré los pelos de la alfombra.

No volveré a dormir sobre las sábanas

en que nos hicimos aguas

y salivas blancas de lamernos.

Quemaré el laurel en esta casa.

Con azúcar andaré quemando las pieles y la carne.

Quemaré el laurel en los latidos.

De Seducción de los venenos, Santiago, LOM, 2008, p. 58. 


\section{Mi fragmento}

Mi país se llama Chile

Aquí,

yo floto herida naufrago

El jardín de placentas que pronuncia mi nombre

se llama Chile

Ya no puedo escaparme del Edén

porque mi paraíso de muertes y atentados

Mi cárcel de aire y de tortura

Las cabezas con gusanos que yo amo

están aquí

Mi fragmento

Mi fragmento

Lo que me pertenece

Lo que me quitaron

Mi mudez se llama Chile

Mi látigo

Los asesinos

Mi duelo

La venganza de laureles

Maleficios

Troncos rotos

Sacrificio de gallinas

Es la sangre revuelta con la tierra

Corazones sudando en mi bandera sin estrella

Ya te digo

Ya te digo

Yo no puedo escaparme del Edén

De Trewa ko, Santiago, Del Aire Ediciones, 2018, p. 86. 


\section{Voy a incendiar esta ciudad}

sus casas

Voy a quemarte lentamente los cabellos

para que no olvides la herida

Mi herida

el puñal con el que tantas veces trataste de matarme

Voy a quemarte el rostro

los rostros en los cuales te miraste el deseo

Arderán como muñecas plásticas las palabras con las que nunca pudiste acariciarme

Voy a incendiar esta ciudad

tus pasos

todo árbol de un de pronto será llamas

Yo misma me quemaré las manos y los ojos

el vestido

a pedazos se caerá mi cuerpo oscuro

y no me dolerá

no voy a quejarme

porque la ciudad (tu ciudad) arderá conmigo

De Dentro de ti hay un asesino que me gusta (inédito) 
Roxana Miranda Rupailaf (Osorno, 1982). Poeta mapuche-williche. Profesora de Lengua Castellana y Comunicación de la Universidad de Los Lagos y magíster en Literatura Hispanoamericana Contemporánea de la Universidad Austral. En los años 2006 y 2008, obtuvo la beca para escritores del Consejo Nacional del Libro y la Lectura por los libros inéditos Seducción de los venenos e Invocación al Shumpall, respectivamente. Participa en las antologías Hilando en la memoria (2006) e Hilando en la memoria. Epu eupa (2009), figurando como editora en la última. En 2012 recibió el Premio Municipal de Literatura de Santiago por Shumpall (2011). Ha publicado: Las tentaciones de Eva (2003), Seducción de los venenos (2008), Shumpall (2011 y 2018), Kopuke Filu (2017) y Trewako (2017). 


\section{JAIME LUIS HUENÚN VILLA}

\section{Los viajes, las vigilias}

1.

Izamos la bandera de la nieve

en nuestros huesos,

-las estrellas de la muerte río arriba-

y caímos al barranco.

Fuego hicimos,

blanco fuego

en la noche aullante de las piedras.

Cómo te llamas, río.

Cuál es tu nombre, árbol.

Dónde te mueres, viento.

Escuchan los caballos ahora

el rumor de nuestra sangre

en el sueño.

Mañana uno de ellos caerá

bajo el hacha de nuestra hambre.

En la roca lucirá su cráneo

como un sol diminuto

en el limpio amanecer de las montañas.

[...]

4.

Me dieron la tierra roja

y oscuros bailes y cantos

para despertar.

Mi tierra,

la cuenca vacía de los dioses,

las playas de greda ante el furor del sol

y montes quemados en la raíz y el aire.

Aquí las piedras labradas desde el sueño. 
Aquí palabras ocultas bajo el viento.

Mi tierra,

andándome con cardos y pastores,

hundiendo su luna en mi mirada.

Nada más allá de mi mirada,

nada sino la ceniza

que el oleaje deja a las rocas

y a los bosques frente al mar.

Mi tierra,

el salto de culebras de espesura

abriendo la neblina en los juncales.

Mi tierra,

los muertos en el arco del conjuro

bailando y delirando bajo el sol.

Mi tierra,

la danza,

el lento apareo después de la embriaguez.

De Reducciones,

Santiago, LOM, 2012, p. 33. 


\section{Entierros}

Aura de las Aguas, Elías Huenún, Ezequiel enterrado en los llanos de Osorno. Todos mis parientes aferrados a las llamas, bruñidos por el oro de las hechicerías.

Te diré, hijo mío, que soñé con Herminda. Venía ella a buscarme vestida como novia. Vamos, me decía, allá donde yo vivo, todo es tan bonito y no me falta nada. Después se me allegaron unos niños oscuros, la cara me escupieron entre sueño y vigilia. Un tiuque hizo su nido en el techo de alerce, mi nieta lo espantó con agua y sal batida. Aura de las Aguas, Elías Huenún, acérquense a la tierra que arde por las noches, al pozo, al gallinero, a los blancos manzanos, al ruido de cadenas chocando en los cimientos. Mi casa levantada sobre el oro y la plata, mi casa construida sobre fuego y miseria, mi casa iluminada por caballos fantasmas, mi casa abrió su puerta a la muerte y al alba. Ahora es Francisca Huenún la que yace mirándome entre flores y cirios encendidos. Afuera los parientes caminan y se pasan de mano en mano el vino, la carne, las palabras. La madre de mi huerto se va con la mañana. La siguen los cerezos, los sauces, las campanas. La madre de mis sueños, pequeña y enterrada, me deja como herencia su sombra fatigada. Te diré, hijo mío, que he visto sabandijas bajando de mi cama apenas raya el día. Por eso me hago cruces de fuego y de ceniza y santiguo mi frente con agua y sal bendita. Aura de las Aguas, Elías Huenún, 
Catalina, Zulema, Carlos, Margarita, todos mis hermanos nombrados noche a noche en la tierra y el eco de montañas perdidas.

De Reducciones, Santiago, LOM, 2012, p. 129. 
Jaime Luis Huenún Villa (Valdivia, 1967). Escritor williche-chileno. Sus obras, que escribe en español, han sido distinguidas con el Premio Pablo Neruda (2003) y la Beca Guggenheim (2005), entre otros reconocimientos. Dirigió las revistas de literatura y arte Pewma (1993-2000) y Ülmapu (2006-2008). Entre sus libros destacan obras suyas y colectivas: Puerto Trakl (2001), El pozo negro y otros relatos mapuches (2001), 20 poetas mapuches contemporáneos (2003), La memoria iluminada. Poesía mapuche contemporánea (2007), Los cantos ocultos (2008), Lof sitiado. Homenaje poético al pueblo mapuche de Chile (2011), Reducciones (2012), Poetry of the Earth: Mapuche Trilingual Anthology (2014), Fanon city meu (2014) y La calle Mandelstam y otros territorios apócrifos (2016). 


\section{CRISTIAN CAYUPAN MORA}

\section{La casa en la roca}

Si hice que esta piedra fuera mi casa

no fue sino para hallar la luz que nace de ella

porque en cada hogar hay una lámpara hecha de palabras

que se enciende con las iniciales de cada estación

Me detuve a contemplar la luz que emerge de la piedra

porque en el atardecer de un hombre

las cosas se valoran de otra forma

La luz se hace más antigua al pronunciarla

porque hay en ella algo que nos hace susceptibles

al observarla a través de los hombres

Me reconozco en la piedra al mirar sus cimientos

porque su luz atraviesa las manos del albañil

y trasciende el esfuerzo de los que la levantaron

con una sola palabra escrita en la tierra

Esta roca es la sombra de otro lugar que no existe una puerta a medio cerrar que ilumina el peñasco de un modo anterior a la luz

Cuando uno mira las vigas con los ojos de otro

es para darle firmeza a la casa

porque desde sus raíces la piedra es un techo cobijando la claridad

Camino por sus alrededores buscando una respuesta

esa señal que reconocemos desde antes de nacer

y alguien siente unos pasos dentro suyo

unas huellas tan antiguas en él

que fue como si las conociera de memoria

porque esas pisadas las hicieron sus antepasados

Alguien me llama a través de un espejo

y la voz parece acercarse

pero al moverme se aleja en mi interior

Cuando se triza el espejo que siempre permaneció en la casa 
también se rompe el misterio que hay en él

porque es una caverna de cristal que ahora habita adentro del género humano Quién sino el tiempo reconstruye sus muros

haciéndola cada vez más profunda

El tiempo que apenas deja de pasar, no es otro, que un presente rezagado y el pasado que allí empieza es otra capa de ceniza en la memoria del hombre porque la casa se remonta a los orígenes del ser.

De El hombre y su piedra, Valparaíso, Ediciones Inubicalistas, 2016, p. 14. 


\section{Los hombres son atuendos de antiguos dioses}

Las sombras que son empujadas a la tierra con esa bestialidad que desconocemos no son presagio de otra creación sino auspicio de nuestra propia existencia ¿Quién dejamos de ser cuando nacemos alumbrando esa mano misteriosa? Los dioses por su parte escondieron sus sombras en piedras inamovibles El que logra cambiar de sitio la roca materna encuentra también los secretos de esa especie Pero los dioses se extinguieron al emerger los hombres depositando a sus deidades en tumbas de barro Surgió entonces la palabra escrita junto al texto del fruto prohibido El miedo a las serpientes se desarrolló en la memoria remota en la primera letra del árbol genealógico por eso hoy el hombre busca algo que jamás ha perdido sino lo que le han hecho creer que alguna vez sorteó.

De Apología del barro, Santiago, Del Aire Ediciones, 2017, p. 46. 


\section{No estoy aquí todavía}

Soy una palabra herida

carente de idioma y espacio

Una palabra indecible

sin diccionario

ni terruño

Una palabra

que no encontró grupo humano

para ser pronunciada

ni fue sospechada por boca alguna

En qué época dejamos de ser vegetal

para encarnamos en la palabra

materia y espíritu

desnudos, dóciles, humanos.

De Tratado de piedras, Valparaíso, Editorial Conunhueno, 2014, p. 52. 
Cristián Cayupan Mora (Puerto Saavedra, 1985) es uno de los poetas bilingüe con mayor proyección en el ámbito de los estudios de la literatura mapuche e indoamericana. Actualmente es gestor y editor de la Revista Comarcas. Literatura sin Fronteras, que se publica desde el año 2011. Dentro de sus grandes proyectos se encuentra el poemario inédito Piedra Humana, obra que actualiza el conocimiento y los discursos mapuche tradicionales. Ha publicado los poemarios Poemas Prohibidos (2007), Reprimida Ausencia (2009), Usuarios del silencio (2012), Tratado de Piedras (2014), Terruño (2014), El hombre y su piedra (2016) y Apología del barro. Fotra ñi llellipun (2017). Además ha publicado, en coautoría con Ana Nanculef, el libro de investigación etnográfica KuifikeZugu. Discursos, relatos y oraciones rituales en mapuzugun (2016). 


\section{KÜTRAL VARGAS HUAIQUIMILLA}

\section{Cazadora de perlas con cuchillo entre los dientes}

Desde barrancos de nácar

trina el alba su altura.

Ávida de sangre, caza cuellos emplumados frente al mar.

Lanza su hambre en apnea nipona, es una Ama que recoge perlas en costas del Pacífico.

Con edad de colonias,

Alzó una torre de idiomas nuevos por siglos, para anidar estirpes con promesas de amanecer en la sangre del enemigo.

La rabia de Abya yala, siempre indómita incendiando su corazón.

Sima abajo, serpientes de espuma bordan el canto de gato marino, arroja su reflejo al pacto con la ola. Insular flota entre algas y nace flor de hueso limpio.

En su colmillo castas nocturnas son jeringas inyectando estrellas travestidas, viendo el final de los pueblos.

Como ella, enferma estoy de la historia y sus pasillos, húmeda de fugas soy ave que sumerge en sal austral su herencia.

Molusca adosada a huellas de risa en la niebla, huele sangre arbórea en zona de sacrificio. 
Ella, mi amante, mi madre, mi hermana, inmortal, sale del agua vestida de lágrimas.

Cual oruga arrastra la toxina de su belleza.

De Corónicas (inédito) 


\section{Purrun y augurio}

Entró el ave jadeante al círculo, anunció el viento de su manto mi trance, la tierra toda vuelta en paraíso de cristo.

Cortejos de choique tronaron catástrofe, nuestra sangre sin bautismo mancharía los cielos.

Antes de cercos / púas / caballos / espadas y rifles el saqueo comunicó en sueños sus incendios. Anunció el viento en huevos vacíos de treiles el caos de tres barcos buscando siglos de oro.

Recuerdo caer en las plumas de tu frente, armar órbitas de deseo seduciendo árbol plantado en el centro de la noche.

En el eco de cueros y pifilka morí. La memoria de nuestros besos resucitó la tormenta que invoqué para que llenes mis piernas de futuros reinos.

Por paso de relámpago, nací de nuevo lacrimógena.

Con cepos en pies, vestidas de luna y maquinaria.

Drogadas en siglo de luces, partimos a brotar con raíz quebrada en discos sin amor.

Pregunto a este viento que me baila coqueto ¿Qué se siente una tirana desértica en baile de lenguas ardientes hacia abajo? Huayno apretado, Dembow, Techno Zampoñas, Ballenato y Cumbia. Giro de gallinas y rodeo mortal, 
entorpecido por huaso duro en arrebato corralero.

Anunció el viento en mi trance, la tierra toda vuelta en paraíso de cristo.

Pasos culebreando volcánica garganta, ebria de canción.

Anunció el viento una liebre hambrienta de fiesta, pelaje acicalado de equinoccios y lluvias.

Anunció el viento en mi trance tu carne partida, y en el baile de los caídos preparé

una yegua encendida de tiempo y linajes desaparecidos.

Sale el ave jadeante del círculo, danza augurio de besos en textura de flama.

Sale el ave jadeante del círculo

sobre cielo boca arriba, apareando canto de ríos en ascenso.

De Corónicas (inédito) 


\section{Conquista de la yegua}

Las vi, levitando históricas.

Yeguas duras aparecidas

flotando en lodos calientes de la fama.

Sin permiso en corridas de la historia, su baile desierto

y florido de huesos en tierra robada ama el corte descalzo, para invocar sangre sobre un mapa de dolor.

Fueron dos y sumaron en un campo antiguo a hijas en costra de casta espuria.

Si jamás has visto un animal gozar en medio del terror y velocidad de su canto, te muestro en el filo de mis ancas leyendas asidas al rocío de mi boca. Yo, que se siente eufórica antes que histérica, histórica, te invito a marchar en la espalda de ríos, ver sucesos de sangre, si me montas. 
Kütral Vargas Huaiquimilla nació en Calbuco, en 1989, y fue criada en San Juan de la Costa. Hoy es performer, escritora y artista visual, y reside en Valdivia. Su creación problematiza las dimensiones éticas, socioculturales y políticas de la cultura patriarcal-colonial-neoliberal que afecta al pueblo mapuche en su relación con el Estado y la sociedad chilena. El ardor del fuego le sirve como metáfora germen para visibilizar y resistir la violencia de un Estado que margina y precariza la existencia del pueblo mapuche. Entre sus obras destacan: Factory (2016), Plantación, Cosecha, La Edad de los árboles (2017), Arte\&Aseo (2019), Lawentuchefe (2019), Nostalgia de un futuro comic mapuche (2020), MallMapu (2020-21) y Corónicas (inédito). 


\section{DANIELA CATRILEO CORDERO}

Tañi piwke

tañi piwke

piwke piwke

después de veinte años

supe que mi corazón

latía con otro nombre

me fue negado

el sonido de su voz

hasta que desperté

en su palpitar

de trueno

tañi piwke

tañi piwke

piwke piwke.

De El territorio del viaje, Santiago, Archipiélago Ediciones, 2017, s/p. 


\section{Quise adentrarme en el bosque}

comer algunas moras

estirar las piernas en soledad

Saco algunas fotografías:

un escarabajo intenta subir una hoja

al nido de un ave

un zorro contempla el vuelo

de unas libélulas

la huella de un perdigón

incrustada en el tronco

de un roble.

De El territorio del viaje, Santiago, Archipiélago Ediciones, 2017, s/p. 


\section{No hablo de héroes}

Hablo de mujeres

que prenden barricadas

¿Puedo pedir que mi última vista

sea mi calle?

Esa es una guerra

Entre los pacos y mis hermanas

entre jaguares y águilas

donde los neumáticos

no son más que adorno

Una guerra bien triste

donde todos juguemos

que no hay guerra.

De Guerra florida, Santiago, Del Aire Editorial, 2018, p. 162. 
Daniela Catrileo Cordero (Santiago, 1987) estudió Filosofía en el exPedagógico. Durante el 2011 fue becaria de la Fundación Neruda y los años 2012 y 2016 obtuvo la beca de creación literaria que otorga el Consejo Nacional de la Cultura y las Artes. Ha publicado la plaquette Cada vigilia (2007), el poemario Río herido (2013) y el libro colectivo Niñas con palillos (2014), ganador del Premio Mustakis de aquel año. El año 2016 publicó la versión definitiva de Río herido con Edícola Ediciones y en 2017 publica el texto autogestionado El territorio del viaje. En 2018, publica Guerra Florida y en 2019 el libro de cuentos Piñen, que obtuvo el Premio Mejores Obras Literarias, categoría cuento, el año 2020. 


\section{MARIBEL MORA CURRIAO}

\section{La condenada}

I

Teresa Wilms Montt, yo te nombro, viajera condenada al silencio, te pregunto ¿Supiste de mis abuelos mapuche en las montañas? ¿Supiste de sus cantos de sus miedos?

Porque yo miro tu faz, Wilms Montt, y el reflejo de tu alma me devuelve el reflejo de mi alma albergando la alegría secreta de las palabras.

Maldices poeta y es de tal manera tu gesto que mi boca y mis deseos levantan al unísono preces retorciendo las visiones como sierpes de un alma enardecida.

¡No puedes ser mala! te digo.

¡No con esos ojos! ¡No con esas manos!

La bondad del corazón desborda tu cuerpo.

¡No es el mal el que te desgarra!

La ausencia de paz en tu frente no es un interior carcomido...

Es el siglo agonizante de humanas vanidades, como decías.

El terreno fecundo donde abrevar la locura.

II

¿Desde cuándo no duermes?

¿Desde cuándo no duermo? 
La madrugada extraña los sueños de espejos.

Llueve afuera como en Londres. Se deshace la noche.

Los truenos hacen piruetas como en el sur de Chile.

¡Cómo podría explicarte la angustia poeta

ahora que respiras en mi propio pecho!

Ahora que me hablas y te hablo en un lecho mullido

donde mi pewma se detiene

antes del instante siniestro de la respiración apagada.

Wezakepewma wezakedungun años míseros.

Tú y yo tan lejanas en los sudores de clase, Teresa, padeciendo las mismas formas de congoja de las cosas que han enmudecido en la ausencia del amado.

Y tú quizás sólo querías, como yo, un abrazo fuerte eterno como la mirada de un niño.

Y luego dormir para siempre. Querías

que el dueño de ese abrazo no supiera nunca

quién eras ni qué es lo que pensabas.

Que no supiera cómo se amaba y cómo se soñaba

en esos sueños tuyos.

Que no supiera de tus miedos. Y a su vez, supiera todo

en el vértigo de tu mirada

en el vértigo de la caída.

III

¿Y la caída Teresa? Esa palabra que se repite

en el universo de las palabras que se repiten

y se repiten y se repiten y se repiten

demasiadas veces buscando olvidarlas.

La caída de un ángel rebelde

es la creación de un mundo. 
Un mundo dio a luz

la caída de una Eva ingenua

y la caída de un Adán pusilánime y delator

como el corazón psicópata de Caín repitiéndose

cada cierto tiempo

cada ciertas tragedias en la historia.

O la caída más estrepitosa de Lot y de sus hijas

en una vida de sexo sin destino

o con la caída por destino

de su descendencia y todas las descendencias

por los siglos de los siglos.

Como estaba escrito.

IV

En este mundo somos todos huérfanos de amor, como decías,

de tu linaje Wilms Montt que te horfanaba.

¡Y tú me dices que no eres buena!

¡Y yo te digo que no soy buena!

Aunque confieso que alguna vez quise ser santa.

Que he querido escapar de mí igual que tú del origen de la piel y de la sangre, de la humanidad y de la mujerez y de la mapuchidad que a veces oprime. Aunque igual que tú no sabré nunca si soy mala o si soy buena o si soy santa.

Al final solo sé que sufro y que en cada acto humano se solaza su contrario.

Hay un vacío de alma en tu mirada tierras sin espesura en mis palabras. Sombras silencio memoria mapuche 
reiteraciones maniáticas Poesía.

Palabras más que locura.

LOCURA más que visiones.

Ulkantun perdidos en la noche

Perrimontun de las culebras

atravesando la línea que lo separa todo.

Premoniciones en estos versos trasnochados.

De Kollaq de las confinadas (inédito) 
Maribel Mora Curriao nacida en un pequeño pueblo cercano a Panguipulli, región de Los Ríos, es una destacada poeta e investigadora. Profesora de Castellano, licenciada en educación, orientadora educacional y vocacional, magíster en Literatura de la Universidad de Chile y candidata a doctora en Estudios Americanos. Sus publicaciones son individuales o colaborativas e incluyen poesía, cuentos, ensayos, e investigación: El pozo negro y otros relatos mapuches (2001), Mirror earth / Espejo de tierra (2008), Kümedungun / Kümewirin: Antología poética de mujeres mapuche (siglos XX-XXI) (2010) y Perrimontun (2014). 


\section{DAVID ANIÑIR GUILITRARO}

\section{Tengo un Odio que me cobija}

Un Odio reprimido por el Amor

Dentro de mi hay un Odio de wenas ganas

$\mathrm{Y}$ francas intensiones

Tengo un odio religioso

Un Odio de la Puta Madre

Un odio como respuesta al Odio

Un Odio fundado, fecundado y fundido

Un Odio fundamental

Corrosivo

Que sabe a dónde apunta

graxias a este Amor tan pagano.

Aunque a veces me da la weá

Y me contra-ataco...

De Lentium,

Santiago, Del Aire Editorial, 2016, p. 24. 


\begin{abstract}
Ah, claro, se abre una nueva veta en el premio Nobel de literatura 2016/ Bob Dylan obtiene la distinción/ No cacho toda su música/ Aun así el rock de entrada a esas grandes ligas de la literatura/ Música en palabras/ Así que Gabriela Mistral y Pablo Neruda/ Afírmense de sus estatuillas/ Que al poema mundial le inyextaron rock en garrafas./ Prevenidos de la tercera guerra mundial/ Como Violeta o Milanka y la huillicheada completa junto a Lienlaf o Rayen Kutral ka Ayme Painé/ Todos llevan sangre en la música/ Poesía en la sangre/ Así la poesía deja estar relegada al libro/ Circunscripta solo a lxs poetxs/ Volvemos al primitivo ancestro/ Al canto anterior/ Bob Dylan no hizo más que ratificarlo./ Del Ül al blues/ Se reafirma que la poesía/ es música en $\mathrm{Si} /$ en $\mathrm{Fa}$ / en Sol, en Luna y así...
\end{abstract}

De Lentium, Del Aire Editorial, Santiago, 2016, p. 27. 


\section{I.N.E. (Indio No Estandarizado)}

Según el Censo de población y vivienda realizado en Chile Usted se considera:

Flojo

Hediondo

Borracho

Piojento

Malas pulgas

Aborigen

Cabeza de palo

Incivilizado

Canuto

Delincuente

Precolombino

Post Punx Rocker

Autóctono

Folklórico

Indígena (indigente)

Terrorista

Quema Bosques

Exótico

Ilícito Asociado

Camorrero

Muerto de Hambre

Originario

Desterrado

Natural

Salvaje (Sur bersivo)

Arcaico

Mono Sapiens

Mal vividor

Mal Moridor

Analfabeto 
Bárbaro

Inculto

Primitivo

Minoría étnica

Nativo

No nato (siempre kisistes eso)

Polígamo

Guerrero

Indómito

Raza inferior, guerrera pero inferior

Indio kuliao

$\mathrm{O}$

¿Araucano?

Acepciones nunca consultadas a boca mapuche,

Que otro descalificativo más te queda por nombrar

Racista Fuck Triñuke...

Que te quede claro,

Demórate un poco más y di Mapuche,

La boca te quedará ahí mismo.

De Guilitranalwe, Santiago, Editorial Quimantú, 20214, p. 15-16. 
David Aniñir Guilitraro (Santiago, 1971). Poeta y gestor cultural. Se define como mapuche urbano (mapurbe). Ha realizado las performances poéticas Mapurbe: debajo del asfalto (2009), Kalül Trawün (2012), Los hijos de los hijos (2016) y Katrilewfu y AD Mapul (2018), junto a Pedro de Piedra y otros artistas. Ha publicado los libros Mapurbe. Venganza a raiz (2005), Haykuche (2008), Autoretraxto (2014), Guilitranalwe (2015), Lentium (2016) у Ad Mapu Constituyente (2018). Sus poemas han sido incluidos en las antologías Epu mari ulkantufe ta fachantu/20 poetas mapuche contemporáneos (2003) y La memoria iluminada: poesía mapuche contemporánea (2007). 


\section{Javier Milanca Olivares}

\section{Rogativa para que bajemos a Jesús}

Mejor bajamos a ese Jesús, lo desclavamos

y lo dejamos descansar.

Lo acurrucamos en nuestro bosque

o cerquita del fuego para que escuche

en silencio nuestras profecías.

Su Padre lo abandonó

y los suyos ya no practican lo que rezan.

Mejor le decimos a Jesús que se venga con nosotros

¡Que se venga!

Que nuestro Rewe no tiene clavos.

Que se saque esa corona de espinas y se ponga un trarilonko de Foye.

Que se venga con nosotros,

aquí no explotamos al hombre por el hombre

aquí no destripamos la tierra.

Eso sí,

que no se venga a cachiporrear con eso de caminar sobre las aguas, que aquí no estamos para trucos televisivos, (además Kalfukura lo hizo en el Nawel Wapi con menos aspavientos).

Mejor que se moje sus canillas de Wilke y ayude al río a pulir las piedras.

Que no multiplique los panes, pues igual nos alcanzará.

Que no multiplique los peces, pues sabemos pescarlos con nuestras manos.

Ahora, si convierte el agua en vino, no nos vamos a enojar. 
Porque no es cosa de andar despreciando milagros, así como así.

No siga llorando con los brazos en cruz, que acá también sabemos de calvarios.

Vente, Jesús y pelea con nosotros.

Que ya no nos quedan mejillas que colocar.

Vente, Jesús y resucita.

Así como nosotros hemos resucitado.

Mejor bajemos a Jesús y que su sangre no nos siga culpando.

Vente, Peñi Jesús, ahora que muchos están en la cárcel.

¡Mari mari, Jesús!

Ahora y en la hora de todas nuestras muertes, (No diga amén, diga Marichiwew).

De Xampurria: somos del lof de los que no tiene lof, Santiago, Editorial Pehuén, 2015, p. 121. 


\section{Sado-Mapuchismo}

Amarraos los unos a los otros se dijeron. ¡Amarraos los unos a los otros! Ambos se daban pastos de amor mapuche tierno por el día. Ambos se daban amarras de fuego por la noche. Amarras para cordero de entrega en kamaruko. Ñochas vivas en los tobillos y viceversa. Los mismos nudos de corredera para matar baguales, los mismos bozales de wachi para jabalíes soberbios. Y no se soltaban por horas hasta que el miedo empezaba a tener consistencia de asesino. Latigazos de ordeña en las nalgas, pellizcos de hambre por las ingles, pinzas de ropa en los pezones recíprocos. Estrangulaciones amoratadas mutuas sin castidad, escupos desesperados al centro de las babas, rasguños de uña en piedra por las espaldas hasta abrir la sangre, gritos de maldición verdadera hasta abrir las culpas y palabrotas recias hasta abrir los cielos. Palabrotas mapunches, palabrotas winka, palabrotas del barrio y debajo de la tierra, palabrotas de borrachos de mierda. Insultos sucios que ni enemigos. Agua por todos lados cayendo al colchón, el colchón a su rumbo hasta caer en las aguas, sonidos de cachetadas certeras en las mejillas, chirridos de catre al ritmo de la ordeña, lloriqueos de espanto pegados a la pared, hasta que sus almas amansadas en el castigo del amor bravo eran sorprendidas por el amanecer que los volvía tiernos como brotes en wüñol tripantu. Pero ahí empezaban de nuevo, suavidad de musgo durante el día, aspereza de ortiga al advenimiento de la noche:

-Te voy a mojar como pifilka en ayekan- le dijo él

- Te voy a dar como a chancho come papas- respondió ella

- Te voy a dar como a gata ladrona- respondió él

-Te voy a pisar como trigo pa muday- le dijo ella.

Y cualquier accidente bastaba para desafiar la noche y empezar las sesiones del suplicio convenido o ella le dejaba caer un tazón de leche caliente entre las piernas o él le dejaba entrar un chilpén de brasa por el escote. Todo era una venganza, todo era una excusa para iniciar una nueva noche de gritos, golpes y castigos más parecidos al inicio de una guerra.

- ¡Te voy a dar como kultrún en ceremonia! -gritaban juntos para asustar el weñulfe mirón y espantar a las estrellas más santurronas.

Y buscaban sus sogas expertas para empezar a amarrarse y amarse amarrándose. Y una noche se anudaron con tanto brío de amor que nunca más pudieron desatarse. Amulepe taiñ poyen. 


\section{Así parió Nora Catriman}

Como pájara borracha traspasó la puerta. El dolor entró con ella. Esta historia podría ser mejor pero solo había un pellón de oveja picado por garrapatas y un par de choapinos mugrientos en el suelo. En la pieza de arriba respiraban su sueño los patrones igual a los dioses cansados de los cielos que le enseñaron. Entonces, pujó a la manera de sus abuelas antiguas y como había visto hacerlo a las terneras en el monte. El mundo se abrió esa noche por sus piernas y el hueco de un nacimiento iluminó la breve vigilia en que fue libre.

De Wüñolche (inédito) 
Javier Milanca Olivares (Valdivia, 1970). Escritor, músico y poeta williche. Profesor de Historia y Ciencias Sociales y Educador Intercultural para la Educación Básica. En 2008 publica Historias Bellacas. En 2009, se adjudica una Beca de Creación Literaria, otorgada por el Consejo Nacional de la Cultura y las Artes. El año 2010 publica Kiltros. Durante el año 2016, obtiene el Premio Mejores Obras Literarias con su libro Xampurria: somos del lof de los que no tienen lof (2015), reeditado en Perú por Pakarina Ediciones (2017), y actualmente prepara Wünolche, libro que está en proceso de edición. 


\section{María Inés HuenuÑIR Antihuala}

\section{Mapuche Zomo}

Weñankley kiñe zomo

kiñe mapuche ñuke

kizu kalelikey antü

lelikey trümiñ pun

fey chi triümiñ pun

tukuniekefi kizu ñi chamal mew

weñankülekey

welu küme tukukey

tañi trapelakucha ka tañi trarilonko

amun rellmu felekey ñi chapetun

ka kiñe trariwe tukuniekei

Tañi kurügen

wellu küme küzawkey

chew tañi amun amulekey

kizu ñi zungu engu

mapuche ñuke

amun manke reke feleaimi

fey ta yewekelay ñi kurüngen

küme wutrapralekey wente mawiza mew

eimi niemi küme piwke

ka küme molfüñ

poyeneimi kom tami pu püñeñ

amuaimi tami lelfün mew

petu rayütuley kozkülla rayen

tami küme piwke mu

Fey mu ta mañum pian fachi antü

Mapuche ñuke. 


\section{Mujer mapuche}

Triste suspira una mujer, una mujer mapuche, ella, también puede ver, luz de día, oscuridad de noche.

La oscuridad se asemeja, a lo oscuro de su ropa y aunque triste ella maneja, sus lindas joyas de plata.

Cintas de colores, en sus trenzas, lleva una faja roja también ya, ¡no quiere más ofensas! ella trabaja muy bien.

Se acompleja por su piel oscura, se siente falta de comprensión, pero, quiere defender su cultura, lleva su costumbre por tradición. Mujer mapuche, ¡haz como el cóndor! él, pese a su plumaje oscuro, se siente feliz y con gran honor, eleva la tradición del pueblo.

Tú, tienes corazón sincero y tierno, que rebosa de sangre pura, mujer de cariño eterno...

protege a tus niños, ¡con gran ternura!

Amada madre, ¡no te sientas mal! vive tranquila, con serenidad allá, siempre cerca de lo natural, aún florece el copihue, gracias a tu bondad.

De Más allá de ser mapuche, Santiago, Editorial Cofradía, 2018, s/p. 


\section{Pichi Küzawtufe}

Pichi küzawtufe

¡Tunten wutre müley tami namün mew!

feley tami rume pichigen

ürkütuleimi tami küzawun

tami rüpü mew müley wayun

alfeñkülei tami rüpütun chew

tami amupeyem fütrake wingkul mew

tami kizuküzawün.

rume pichiy tami wentrugen

ñi felen tami felen

tami pichichegen

tachi azükintulu upetukey

rume faney chi zimün

¡ta tukuketranmuam!

welu femüngechi zuangenun

alün che iay tami kofke

amuley tami ayelen az

tami rume kümepüñeñgen

zewmayan kiñe

newen kuykuy

nometukeigün kakel che

kiñe ngiyonchi país mew

küzawkeimi weza tukulwün

trunatukeimi kachilla ka üwa

mongeleimi tami ngünezuangenun

kimlafimi ta wingkanemül

ka kimlafimi rakintun

pichi küzawfe nielay kullin

pichi wentrumülelu

lof mapu mew. 


\section{Obrerito}

Pequeño obrerito

¡Cuánto hielo hay en tus pies!

Siendo aún pequeñito

laboras sin detenerte.

Fluyeron tus fuerzas, a causa de la pobreza tu rostro es la pureza, desde el fondo de la tierra.

En tus huellas hay espinas, que hieren tu caminar, tras surcar la colina, con tu propio trabajar.

Siendo un hombre bajito, de natural estatura eres niño pequeñito al destino, se le olvida.

¡Tanto pesa el arado! para poder sembrar aun siendo ignorado muchos comerán tu pan.

Va tu rostro sonriente, con infantil dulzura formando un puente, que todos cruzan.

En un rincón del país, trabajas mal vestido apuñando trigo y maíz, viviendo inadvertido. 
No sabes el abecedario, no conoces numerales, obrerito sin salario niño, de tierras rurales.

De Viento a favor, Santiago, ESE:O Subsecretaría de Previsión Social, 2014, p. 79. 


\section{Meli}

Meli trayen komew choyüpay tañi mongen meli wunman mew zewmay tañi chegen

Meli alfeñ molfüñ mu zewmangey tañi kalül meli witrun molfüñ mu treftreftuy tañi piwke

Meli witran mapu walpay tañi felen rangintu mapu mew choyüpan inche

Meli fütrake lafken ngüretuy tañi lewfü meli mawizantu mew choyütuy tañi neyün

Nien meli kuifikecheyem zewmaleigün kiñe rayen mongetuleigün tañi nge mu eñumtuleigün antü mew

Feyengün tañi küwü mu retrütuley tañi newen kiñe we lelfün mew wenuntuley tañi az

Tañi kuifikecheyem zewmaigün inche tañi rüpü tañi küme amuleam we fillmongen $\mathrm{mu}$ 


\section{Meli (Cuatro)}

Fueron cuatro cauces

que me dieron vida, cuatro amaneceres formaron mi día.

De cuatro sangres rotas mi cuerpo se formó de cuatro venas nuevas mi corazón latió.

Cuatro puntos profundos me hicieron girar en el centro del mundo vine a rebrotar.

Desde cuatro mares se formó mi río, desde cuatro montes nace mi respiro.

Tengo a cuatro ancianos formando una flor su centro son mis ojos abrigados de sol.

Sus manos son mi escudo afirmando el valor en un sitio nuevo digno de mi honor.

Son mis cuatro abuelos marcando mis senderos, protegiendo mi destino de todo el modernismo. 
De Viento a favor, Santiago, ESE:O Subsecretaría de Previsión Social, 2014, p. 29. 
Maria Inés Huenuñir Antihuala (Cayumapu Alto, 1968). Poeta y activista sociocultural mapuche. Participa del poemario colectivo Cuentos de la Tierra, cuentos de la vida (2002). Luego, publica su libro personal Malen Mapu (2003). En el año 2004, publica Más allá de ser mapuche, autofinanciado con un tiraje de 500 ejemplares, que el año 2008 se reedita con 1000 ejemplares, también autofinanciado. Ha participado en difusión radial y en obras de teatro de elenco internacional. En 2010, es reconocida por la JUNJI como Educadora de Lengua y Cultura Indígena, para trabajar en educación inicial. 


\section{MARÍA ISABEL LARA MILLAPAN}

\section{Üy}

Kakekününgi

Niefuiñ üñüm üy,

kulliñ üy ka kura üy

anümka ka rayen chew taiñ choyünmew,

ko üy niefuiñ, fotra ka pire

taiñ pu chuchu taiñ üy

taiñ laku,

müleweki tañi pu reñma mew

ramtumetuiñ chem üy am ta niefuiñ. 


\section{Nombre}

Cuando nos cambiaron los nombres

Teníamos nombres de aves, de animales y de piedras, nombres de árboles y de flores

del territorio donde nacimos, teníamos nombres de agua, de barro y de nieve los mismos nombres de los abuelos se quedaban heredados en sus hijos y en sus nietos vamos a preguntar por el nombre que nos pertenece.

De Trekan Antü, Edición propia, 2019, p. 27. 


\section{Dungun}

Feytachi dungun mew üytükeyu

Feytachi dungun mew allkün tañi pu che,

Feytachi dungun mew feypin

Feytachi dungun mew weychan

Feytachi dungun mew ñi wün mew

Kiñeke mew laken

Welu wiñoketun

Rangi pewma mew

Üñüm tañi ülkantun mew

Lewfu tañi trukur mew, wiñoketun,

Tañi püllü mew, wiñoketun,

Rumel wiñoketun. 


\section{Hablo}

Con este idioma pronuncio tu nombre

Con este idioma escucho los dolores de mi pueblo,

Con este idioma digo

Con este idioma defiendo

Con este idioma en mis labios

A veces muero

Y vuelvo a pronunciarme

En cada sueño

En el canto de los pájaros

En la neblina de los ríos, vuelvo,

Con mi espíritu, vuelvo,

Siempre vuelvo.

(Inédito) 


\section{Mapudungun mew}

Mapudungun mew üytuafuin ko, kürüf ka mapu.

Mapudungun mew

Mütrümafuin wingkul,

Ka kimtukuafun relmu ñi dungun.

Mapudunguli, allkütuafun tralkan,

Fey kimafun, chem dungu mew ñi femün,

Ka kimafun dewma tripapale antü,

Tañi chumngechi mongelen. 


\section{En mapudungun}

En mapudungun puedo nombrar el agua, el viento, la tierra.

En mapudungun, puedo llamar a las montañas

Y entender el mensaje de los arcoíris.

Si hablara mapudungun,

Podría entender la tormenta como una respuesta

Y la salida del sol

Como el origen de la vida.

De Ale / Luz de la Luna, Edición propia, 2012, p. 15. 
María Isabel Lara Millapan (Chihuimpilli, 1979). Poeta y hablante nativa de mapudungun. Es máster y doctora en Didáctica de la Lengua y Literatura por la Universidad Autónoma de Barcelona, Cataluña, académica de la Pontificia Universidad Católica de Chile e investigadora asociada del Centro de Estudios Interculturales e Indígenas, CIIR. Ha publicado los siguientes textos: Puliwen ñi pewma. Sueños de un amanecer (2002), Ale/Luz de la luna (2012), Aukiñko (Chile, 2014), un disco de poesía Kimün. Aprendiendo mapudungun a través de poesías y relatos (2014), Trekan Antü. Poesía mapuche (2018). Es coautora del libro Zomo Newen. Relatos de vida de mujeres mapuche en su lucha por los derechos indígenas (2017).

Su escritura poética ha sido antologada en Epu Mari ulkantufe ta fachantu. 20 poetas mapuche contemporáneos (2003), Hilando en la memoria (2006), La memoria iluminada: poesía mapuche contemporánea (2007) y Rayengey ta dungun. Pichikeche ñi mapuche kumwirin. La palabra es flor, poesía mapuche para niños (2011). 